\title{
Occurrence of bufotenin in the Osteocephalus genus (Anura: Hylidae)
}

\author{
T.O.G. Costa ${ }^{\mathrm{a}, \mathrm{b}}$, R.A.V. Morales ${ }^{\mathrm{c}}$, J.P. Brito ${ }^{\mathrm{c}}$, M. Gordo ${ }^{\mathrm{d}}$, A.C. Pinto ${ }^{\mathrm{b}}$, C. Bloch Jr. ${ }^{\mathrm{c}, *}$ \\ ${ }^{a}$ Laboratório de Produtos Naturais, Dept de Química Orgânica, Universidade Federal do Amazonas, \\ Estrada Gal. Rodrigo Otávio Jordão Ramos, 3000, Aleixo CEP 69077-000, Manaus-AM, Brazil \\ ${ }^{\mathrm{b}}$ Laboratório de Síntese Orgânica e Produtos Naturais, Instituto de Química, Universidade Federal do Rio de Janeiro, \\ CEP 21941-590 Ilha do Fundão, Rio de Janeiro-RJ, Brazil \\ ${ }^{\mathrm{c}}$ Laboratório de Espectrometria de Massa, Embrapa Recursos Genéticos e Biotecnologia, P.O. Box 02372, Brasília-DF, Brazil \\ ${ }^{\mathrm{d}}$ Departamento de Biologia, Instituto de Ciências Biológicas, Universidade Federal do Amazonas, Estrada Gal. Rodrigo Otávio Jordâo Ramos, \\ 3000, Aleixo CEP 69077-000, Manaus-AM, Brazil
}

Received 29 January 2004; revised 28 January 2005; accepted 1 February 2005

Available online 27 July 2005

\begin{abstract}
Bufotenin (5-hydroxy- $N, N$-dimetyltryptamine) is a tryptamine alkaloid widely spread among anuran families as a component of their chemical defense system, acting as a potent hallucinogenic factor, showing similar activity to LSD upon interaction with the $5 \mathrm{HT}_{2}$ human receptor. This work demonstrates the presence of bufotenin in the skin secretion of three arboreal amphibian species of the Osteocephalus genus (Osteocephalus taurinus, Osteocephalus oophagus and Osteocephalus langsdorffi) from the Amazon and the Atlantic rain forests using RP-HPLC, ESI-MS/MS, UV, IR and multidimensional NMR techniques. To our knowledge, this is the first description of bufotenin in the Osteocephalus genus, so far.
\end{abstract}

(C) 2005 Elsevier Ltd. All rights reserved.

Keywords: Bufotenin; Osteocephalus; Tryptamine alkaloid; ESI/MS/MS; NMR

\section{Introduction}

Bufotenin (5-hydroxy- $N, N$-dimetyltryptamine) is a tryptamine alkaloid, such as serotonin, $N$-methylserotonin, 5-methoxy- $N$-methyltryptamine and melatonin, widely distributed in the Leguminosae family (Smith, 1977) and commonly found in a number of vertebrates as mammals (Forsström et al., 2001) and in many amphibian groups around the world as reported by Roseghini and colleagues (Cei and Erspamer, 1966; Cei et al., 1972; Roseghini et al., 1986, 1988; Erspamer, 1994).

\footnotetext{
* Corresponding author. Tel.: +55 61448 4636; fax: + 5561340 3658.

E-mail address: cbloch@cenargen.embrapa.br (C. Bloch).
}

In humans, these molecules show potent psychotropic properties and it is usually associated to temporary mental disorders and brain diseases such as schizophrenia and other psychotic symptoms, probably due to its similar physiological and structural features to LSD in the 5HT2 receptor (Räisanen and Kärkkäinen, 1979; Takeda et al., 1995). In amphibians this molecule is usually associated to a prey defense mechanism by its noxious properties (Duellman and Trueb, 1986).

The present study investigates the first occurrence of bufotenine in the skin secretion of three amphibian species of Osteocephalus genus (Osteocephalus taurinus, Osteocephalus oophagus and Osteocephalus langsdorffii) collected in the Brazilian Amazon and Atlantic rain forests. Osteocephalus specimens are medium-sized to large spiny-backed tree frogs widely distributed throughout 
the Amazon Basin, the Guiana Shield, and the Atlantic Forest of southeastern South America.

Up to now, it has been recognized only 16 species of this genus with little information on the chemical composition of their skin secretion (Jungfer and Hodl, 2002). To perform this work, we used RP-HPLC, ESI-MS/MS, IR, UV and multidimensional NMR techniques to confirm the presence of bufotenine and other potentially bioactive compounds.

\section{Materials and methods}

\subsection{Skin secretions}

Seven adult specimens (both sexes) of $O$. taurinus and six of $O$. oophagus were collected at the Brazilian Amazon rain forest nearby the city of Manaus-AM and three adult specimens of $O$. langsdorffi $i$ were collected at the Brazilian Atlantic rain forest around the city of Santa Tereza-ES, under the Instituto Brasileiro do Meio Ambiente e Recursos Renováveis (IBAMA) license 097/96-DIFAS, process number: 0637/91A.C.

The skin secretions were obtained by mild electrical stimulation (6 V), collected in Milli-Q water (Millipore), frozen with liquid nitrogen, lyophilized and stored at $-80{ }^{\circ} \mathrm{C}$.

\subsection{Bufotenin purification}

The crude skin secretion was fractionated by RP-HPLC, using a LC 10 VP (Shimadzu Co.) with a semi-preparative C18 column (218TP1010, Grace Vydac) in a linear acetonitrile gradient containing $0.1 \%$ TFA performed in 60 min. Bufotenin fractions were submitted to a further purification step using an analytical C18 column (218TP54, Grace Vydac). The experiments were monitored simultaneously at 216 and $280 \mathrm{~nm}$ and fractions were collected manually.

\subsection{Mass spectrometry}

The purified bufotenin HPLC fractions (Ota6, Oop6 and Ola6) were submitted to ESI/MS analysis configured for identification of positive loads using Quattro II equipped with a Z-spray Ion Source (Micromass, UK).

The ionization parameters adopted for the MS and MS/MS analysis were: desolvatation temperature of $150{ }^{\circ} \mathrm{C}$, block temperature of $90^{\circ} \mathrm{C}$, cone voltages of 10 and $20 \mathrm{eV}$, and capillary voltage of $4.20 \mathrm{kV}$. Nitrogen was used for solvatation and nebulization. For the fragmentation studies, the collision voltage was adjusted to $33.0 \mathrm{~V}$.

The precursor ions found at $\mathrm{m} / \mathrm{z} 205 \mathrm{Da}$ in each sample was submitted to fragmentation using Argon as the collision gas. The data were processed and analyzed using MassLynx software provided by the manufacturer.

\subsection{Spectral analysis}

Four milligrams (approximately $20 \mathrm{mM}$ ) of Ota6 were dissolved in $\mathrm{CD}_{3} \mathrm{OD}$ and submitted to ${ }^{1} \mathrm{H}$ and ${ }^{13} \mathrm{C}$ NMR (Bruker AVANCE ${ }^{\mathrm{TM}}$ DRX $400 \mathrm{MHz}$ ) studies in conjunction with COSY, HSQC and HMBC experimental analysis. Infrared spectra (IR) were recorded with a Nicolet-MagnaIR 760 series Fourier transform spectrometer using $\mathrm{KCl}$ plates and ultraviolet spectra (UV), recorded with a RP-HPLC (Waters model 510 pump and a model 996 photodiode UV detector), using a semi-preparative C18 column (Waters ${ }^{\circledR} \mu$ Bondapak $^{\mathrm{TM}}$ ).

\section{Results}

The RP-HPLC fractionation of skin secretion from $O$. taurinus, $O$. oophagus and $O$. langsdorffi yielded at least 15 fractions, the major ones found in each specie, were named Ota6, Oop6 and Ola6, respectively. Their elution times were consistently observed at $22.5 \mathrm{~min}$ for all three species throughout the HPLC experiments (Fig. 1). Minor fractions were also mass analyzed and the preliminary results indicated the presence of antimicrobial peptides and serine proteinase inhibitors (data not shown).

Fraction Ota6, gave UV absorptions at 287.5, 277.0, 271.0 and $237.5 \mathrm{~nm}$ suggesting the presence of at least one unsubstituted indole structure in the position-2 (data not shown). IR bands at 3400, 3300, 2980 (weak) and $1622 \mathrm{~cm}^{-1}$ indicating the indole $\mathrm{NH}, \mathrm{OH},-\mathrm{CH}_{2}-$ from the aliphatic chain and aromatic ring (data not shown), respectively. The NMR spectrum of sample in $\mathrm{CD}_{3} \mathrm{OD}$ revealed a $6 \mathrm{H}$ singlet at $2.85 \mathrm{ppm}$ for the $\mathrm{N}\left(\mathrm{CH}_{3}\right)_{2}$ group and $4 \mathrm{H}$ methylene signals $\left(\mathrm{A}_{2} \mathrm{X}_{2}\right.$ system) between 3.00 and $3.40 \mathrm{ppm}$, that can be due to an $\mathrm{Ar}-\mathrm{CH}_{2}-\mathrm{CH}_{2}-\mathrm{N}$ group, characteristic of protons in the side chain of $\mathrm{N}, \mathrm{N}$ dimethyltryptamine. Signals corresponding to four protons were found in the aromatic region. Proton H-2 appears as a weakly broadened signal at $7.10 \mathrm{ppm}$. The three protons of the six-membered ring form an ABC-system typical of this type of substituted benzene ring. Proton $\mathrm{H}-4$ resonates at $6.90 \mathrm{ppm}$ and proton H-6 appears as a doublet of doublet at $6.76 \mathrm{ppm}$. Finally, the doublet for $\mathrm{H}-7$ is observed at $7.29 \mathrm{ppm}$.

ESI-MS analysis of Ota6 and analogues (Fig. 1) show the presence of bufotenine as the major component in each chromatographic fraction and its ion source fragmentation products (Fig. 2) confirmed by the MS/MS experiments. MS/MS analysis of Ota6 and analogues at three different collision energies yielded a single ion of 205.16 Da $\left(\mathrm{M}+\mathrm{H}^{+}\right)$with a fragmentation pattern, characterized by the following daughter ions: $160.1 \mathrm{Da}\left(\mathrm{C}_{10} \mathrm{H}_{9} \mathrm{NO}\right)$ $\left(\mathrm{M}+\mathrm{H}^{+}\right)$and $132 \mathrm{Da}\left(\mathrm{C}_{9} \mathrm{H}_{9} \mathrm{~N}\right)\left(\mathrm{M}+\mathrm{H}^{+}\right)$, corresponding to charge-site-initiated-fragmentation accompanied by hydrogen atom rearrangement, leading the loss of $\mathrm{C}_{2} \mathrm{H}_{7} \mathrm{~N}$ $(45.0 \mathrm{Da})\left(\mathrm{M}+\mathrm{H}^{+}\right)$and $\mathrm{C}_{3} \mathrm{H}_{8} \mathrm{~N}(58.2 \mathrm{Da})\left(\mathrm{M}+\mathrm{H}^{+}\right)$ 


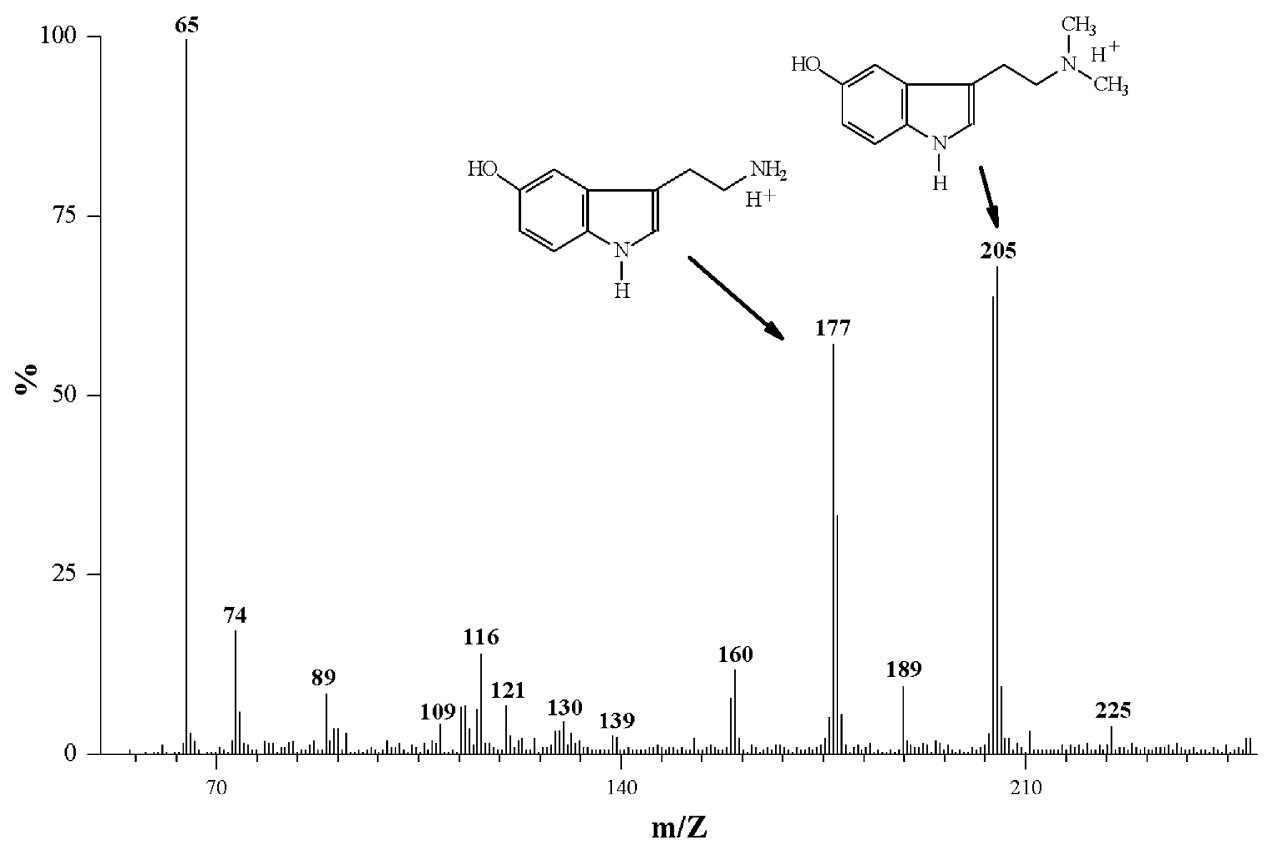

Fig. 1. RP-HPLC chromatograms of skin secretion from Osteocephalus taurinus (Ota), Osteocephalus oophagus (Oop) and Osteocephalus langsdorffs (Ola) with a semi-preparative $\mathrm{C} 18$ column. The analysis were performed using a linear acetonitrile gradient containing $0.1 \%$ TFA, in $65 \mathrm{~min}$ and the major component of each sample is identified.

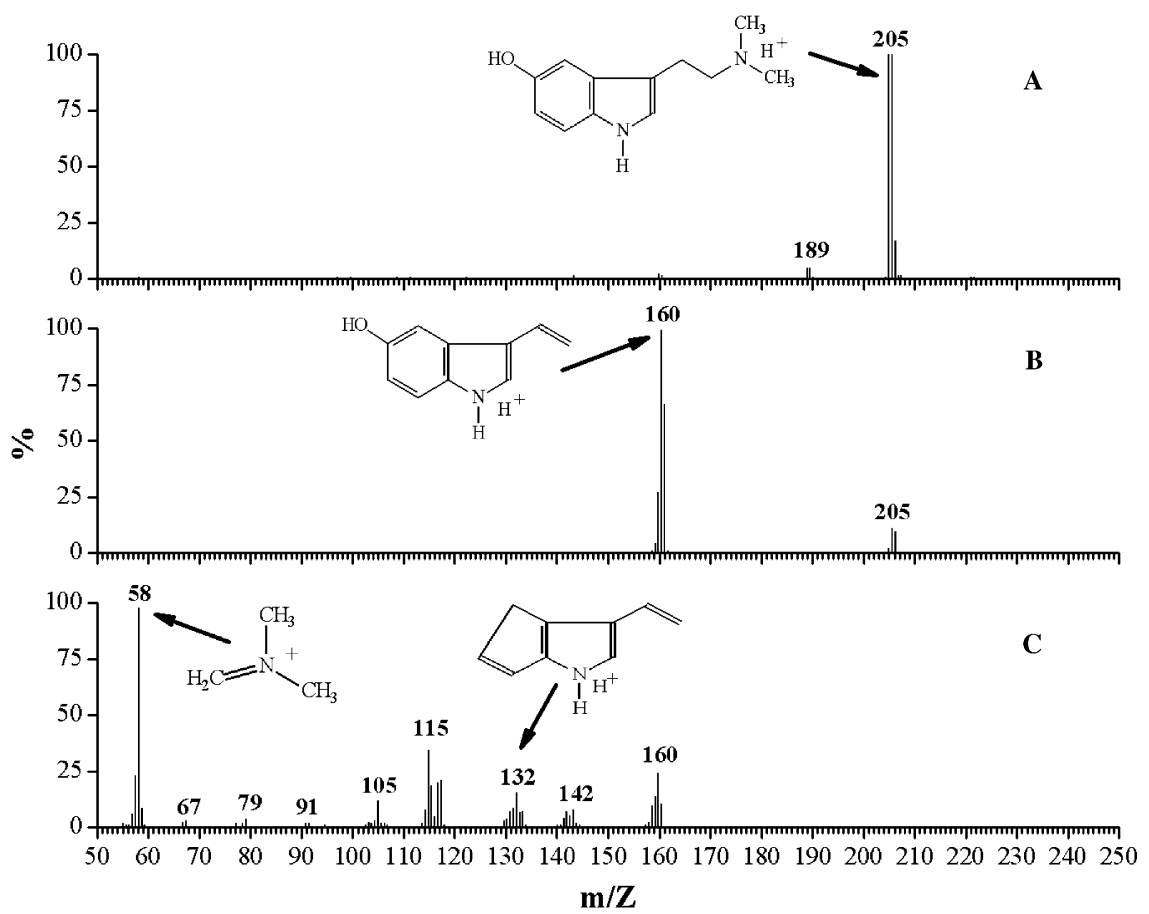

Fig. 2. ESI-MS analysis of the major fraction of O. taurinus (Ota6) skin extracts showing the presence of bufotenine (205 Da), serotonin $(177 \mathrm{Da})$ and $N, N$-dimetyltryptamine $(189.0 \mathrm{Da})$ as its major in source fragmentation product. 


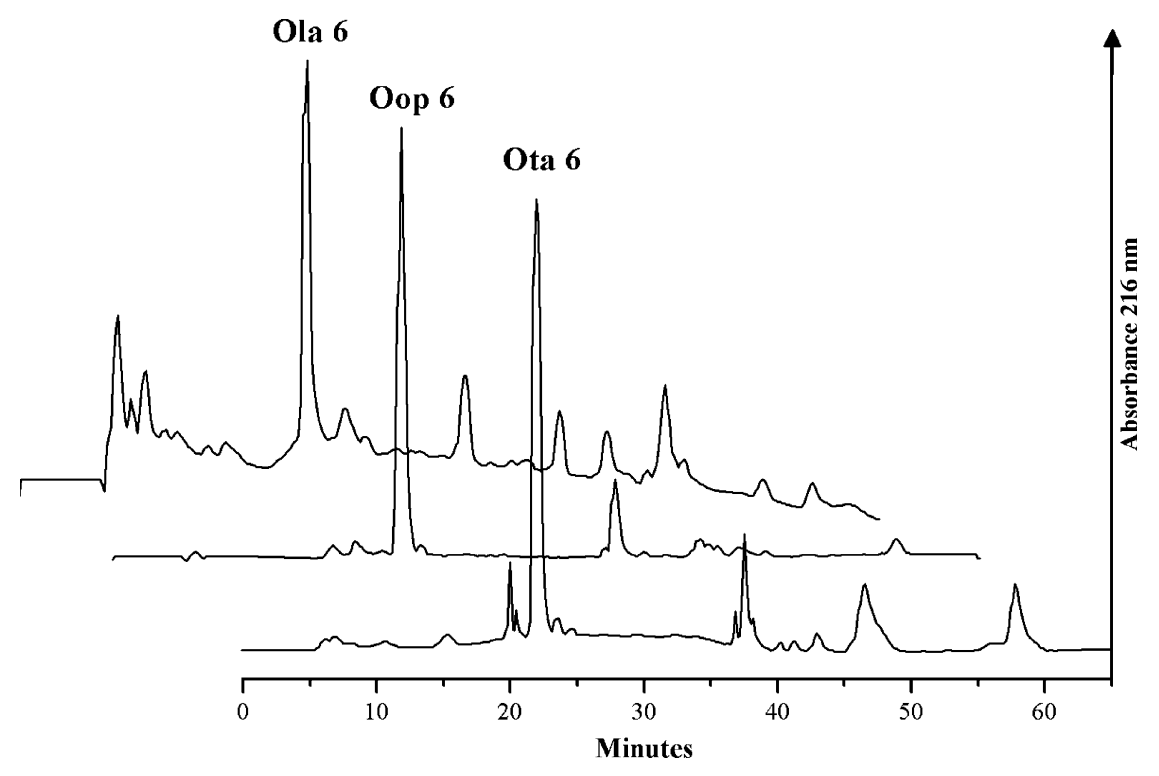

Fig. 3. ESI-MS/MS analysis of the ion $205 \mathrm{Da}\left(\mathrm{M}+\mathrm{H}^{+}\right)$with different collision energy voltages $A(0 \mathrm{eV}), B(10 \mathrm{eV})$ and $C(20 \mathrm{eV})$. The identification as bufotenin was achieved by its fragmentation pattern, characterized by the following daughter ions: $160 \mathrm{Da}\left(\mathrm{C}_{10} \mathrm{H}_{9} \mathrm{NO}\right)$ $\left(\mathrm{M}+\mathrm{H}^{+}\right), 132 \mathrm{Da}\left(\mathrm{C}_{9} \mathrm{H}_{9} \mathrm{~N}\right)\left(\mathrm{M}+\mathrm{H}^{+}\right), 58 \mathrm{Da}\left(\mathrm{C}_{3} \mathrm{H}_{8} \mathrm{~N}\right)\left(\mathrm{M}+\mathrm{H}^{+}\right)$and $45 \mathrm{Da}\left(\mathrm{C}_{2} \mathrm{H}_{7} \mathrm{~N}\right)\left(\mathrm{M}+\mathrm{H}^{+}\right)$.

obtained upon cleavage of the amine ring substitution between methylenes (Fig. 3). The samples Oop6 and Ola6 were also analyzed by ESI-MS showing the same molecular mass and fragmentation pattern (data not shown).

\section{Discussion}

The major components of the HPLC fractionations (Ota6, Oop6 and Ola6), from each skin secretion samples of the three Osteocephalus frogs species, were analyzed by IR, mass spectrometry and NMR. As described in previous works, the mass analyses performed on these fractions are in perfect agreement with those found for the bufotenin molecule (McClean et al., 2002), in fact, a single step of reverse phase chromatography yeilded a major fraction containing bufotenin (205.0 Da) that was effortless detected by ESI/MS together with its ion source fragmentation products, such as serotonin $(177.0 \mathrm{Da})$ and $N, N$-dimetyltryptamine (189.0 Da) (Fig. 2).

Moreover, 1D and $2 \mathrm{D}-{ }^{1} \mathrm{H},{ }^{13} \mathrm{C}$ NMR spectra, including COSY, HSQC and HMBC experiments, were consistent with those found in the 5-hidroxy- $N, N$-dimethyltryptamine (Somei et al., 2001; Revial et al., 2002), giving a strong evidence that bufotenin was present in all the three samples analyzed.

Roseghini and colleagues in their screening work for bioactive compounds on amphibian groups had described 5-HT and leptodactyline in skin secretions of O. taurinus but failed to report the presence of bufotenine. This was probably due to variations in individual natural abundance according the sex, season, diet and among the populations (Daly et al., 2002; Pires, 2002).

The present findings not only support the general idea that different amphibian families share a common chemical defense system but also show that closely related species with significant geographical dispersion, could display highly conserved pattern of bioactive compounds in their skin secretions. The peptide and protein content present in the skin secretions of the three species investigated here will be reported elsewhere.

\section{Acknowledgements}

The authors wish to thank Dr Lenize F. Maia and Dr Ana Paula Valente (Centro Nacional de Ressonância Nuclear, Departamento de Bioquímica Médica-ICB/CCS-UFRJ) for spectrum of NMR and Dr José Pombal Júnior (Museu Nacional do Rio de Janeiro/UFRJ) for collection and identification of $O$. langsdorffii.

\section{References}

Cei, J.M., Erspamer, V., 1966. Biochemical taxonomy of south American amphibians by means of skin animes and polypeptides. Copeia 1, 74-78.

Cei, J.M., Erspamer, V., Roseghini, M., 1972. Biogenic amines. In: Blair, F. (Ed.), Evolution in the Genus Bufo. University of Texas Press, Austin, TX, pp. 233-243.

Daly, J.W., Kaneko, T., Wilham, J., Garraffo, H.M., Spande, T.F., Espinosa, A., Donnelly, M.A., 2002. Bioactive alkaloids of frog 
skin: combinatorial bioprospecting reveals that pumiliotoxins have an arthropod source. Proc. Natl Acad. Sci. 99 (22), 1399614001.

Duellman, W.E., Trueb, L., 1986. Biology of Amphibians. McGraw-Hill Book Company, New York, p. 228.

Erspamer, V., 1994. In: Heatwole, H., Barthalmus, G.T. (Eds.), Bioactive Secretions of the Amphibian Integument Amphibian Biology. The Integument, vol. 1. Ed Surray Beatty and Sous, Chipping Norton, Australia, pp. 178-350.

Forsström, T., Tuominen, J., Karkkainen, J., 2001. Determination of potentially hallucinogenic $N$-dimethylted indoleamines in human urine by HPLC/ESI-MS-Ms. Scand. J. Clin. Lab. Invest. 61, 547-556.

Jungfer, K., Hodl, W., 2002. A new species of Osteocephalus from Ecuador and a redescription of $O$. leprieurii (Dumeril and Bidron, 1841). Amphibia-Reptilia 23 (1), 21-28.

McClean, S., Robinson, R.C., Shaw, C., Smyth, F., 2002. Characterization and determination of indole alkaloids in frogskin secretions by electrospray ionization ion trap mass spectrometry. Rapid Commun. Mass Spectrom. 16, 346-354.

Pires Jr., O.R., 2002. Ocorrência de Tetrodotoxina e Derivados em Três Espécies de Brachycephalus (Amphibia:Anura:Brachycephalidae). PhD. Thesis, Universidade de Brasilia, p. 150.

Räisanen, M., Kärkkäinen, J., 1979. Mass fragmentographic quantification of urinary $\mathrm{N}, \mathrm{N}$-dimethytryptamine and bufotenine. J. Chromatogr. 162, 579-584.
Revial, G., Jabin, I., Lim, S., Pfau, M., 2002. Aromatization of $1,6,7,7$ a-tetrahydro-2H-indol-2-ones by a novel process. Preparation of key-intermediate methyl 1-benzyl-5-methoxy-1Hindole-3-acetate and the syntheses of serotonin, melatonin, and bufotenin. J. Org. Chem 67 (7), 2252-2256.

Roseghini, M., Erspamer, V., Falconieri, G., Cei, J.M., 1986. Indole-, imidazole- and phenil-alklamines in the skin of one hundred and forty American amphibian species other than Bufonids. Comp. Biochem. Physiol. 85C (1), 139-147.

Roseghini, M., Falconeri, G.E., Severini, C., 1988. Biogenic amines and active peptides in the skin of fifty-two African amphibian species other than bufonids. Comp. Biochem. Physiol. 91C (2), 218-286.

Smith, T.A., 1977. Tryptamine and related compounds in plants. Phytochemistry 16, 171-175.

Somei, M., Yamada, F., Kuraushi, T., Nagahama, Y., Hasegawa, M., Yamada, K., Teranishi, S., Sato, H., Kaneko, C., 2001. The chemistry of indoles. CIII. Simple syntheses of serotonin, $N$-methylserotonin, bufotenine, 5-methoxy- $N$-methiltryptamine, bufobutanoic acid, $N$-(indol3-yl)methyl-5-methoxy- $N$-methyltryptamine, and lespedamine based on 1-hydroxyindole chemiytre. Chem. Pharm. Bull. 49 (1), 87-97.

Takeda, N., Ikeda, R., Ohba, K., Kondo, M., 1995. Bufotenine reconsidered as a diagnostic indicator of psychiatric disorders. Neuroreport 6 (17), 2378-2380. 